\title{
HPLC Quantification and MS/NMR Confirmation of Javamide-I/-II in Arabica and Robusta Coffee Beans from Different Regions for Finding Better Bean Sources for Javamide-I/-II
}

\author{
Park J B ${ }^{1 *}$, Wang YTT ${ }^{1}$, Zhang $\mathrm{D}^{2}$, Vega $\mathrm{EF}^{2}$ and \\ Meinhardt WL ${ }^{2}$ \\ ${ }^{1}$ Diet, Genomics, and Immunology Laboratory, USA \\ ${ }^{2}$ Department of Agriculture, Sustainable Perennial Crop \\ Laboratory, USA \\ *Correspondling author: Jae B. Park, Diet, Genomics \\ and Immunology Laboratory, USDA, Beltsville, USA
}

Received: December 17, 2018; Accepted: January 10, 2019; Published: January 17, 2019

\begin{abstract}
Coffee is a popular drink with several positive health effects and javamide$\mathrm{I} /-\mathrm{II}$ are bioactive phenolic amides found in coffee. However, there is little information about the quantities of javamide-I/-II in Arabica and Robusta beans from different geographical regions, impossible to categorize better bean sources for javamide-I/-II. Therefore, in this paper, javamide-I/-II were first extracted from twelve coffee beans (eight Arabica beans from Brazil, Colombia, Costa Rica, Ethiopia, Hawaii, Papua New Guinea, Puerto Rico and four Robusta beans from India and Vietnam), and their amounts were quantified using the developed HPLC method with MS/MS and NMR confirmation. In eight Arabica beans, javamide-I/-II were detected at levels ranging from 0.04-0.05 and 0.08-0.29 $\mathrm{mg} / \mathrm{g}$, meanwhile $0.4-0.76 \mathrm{mg} / \mathrm{g}$ of javamide-I and $3.5-4.9 \mathrm{mg} / \mathrm{g}$ of javamide-II were detected in four Robusta beans. The data showed that the amounts of javamide-I/-II in Robusta beans were much higher than those of javamide-I/ II in Arabica beans with little geographical impact $(P<0.05)$. To validate these data and to explore better coffee beans for javamide-I/-II, eight additional beans (four Arabica and four Robusta beans) were extracted to examine the amounts of javamide-I/-II. The data of the eight additional beans confirmed the data of the twelve coffee beans in the levels of javamide-I/II $(P<0.05)$, suggesting that Robusta beans may be better sources for javamide-I/-II than Arabica beans. In summary, javamide-I/-II may be found at higher levels in Robusta beans than Arabica beans, and Robusta beans are likely to be better bean sources for javamide-I/-II.
\end{abstract}

Keywords: Javamide-I/-II; MS/MS; NMR; HPLC quantification; Unroasted coffee beans

\section{Introduction}

Coffee is a tropical evergreen tree grown around the globe and coffee beans are typically used to produce a popular drink [1-3]. In fact, Coffea arabica (Arabica coffee) and C. canephora (Robusta coffee) are two most commercially important coffee species, primarily cultivated in the equatorial regions of the Americas, Southeast Asia, India, and Africa [3-7]. Arabica and Robusta beans are also known to contain numerous chemicals (e.g., caffeine, chlorogenic acids, javamide-I/-II, others) [7-9]. Recently, javamide-I/-II and their derivatives were reported to contain several biological activities related to human health [10-12]. However, there is little information about the amounts of javamide-I/-II in Arabica and Robusta beans from different geographical regions, although there are increasing inquiries about coffee beans with high amounts of javamide-I/-II and geographical impacts on them $[7,8]$. Therefore, in this paper, javamide-I/-II in twelve coffee beans (eight Arabica and four Robusta) grown in Brazil, Colombia, Costa Rica, Ethiopia, Hawaii, Papua New Guinea, Puerto Rico, India and Vietnam were first extracted and their identities were confirmed by MS/MS and NMR spectroscopic method. Then, javamide-I/-II were quantified using a HPLC method to gauge the influences of species and geographical influences on javamide-I/-II. Also, to validate the data of the twelve beans and to identify better bean sources for javamide-I/-II, eight additional coffee beans (four Arabica and four Robusta beans) from different regions were purchased and the amounts of javamide-I/-II were further quantified using the developed HPLC method.

\section{Materials and Methods}

\section{Chemicals and reagents}

Javamide-I/-II standards were prepared as reported previously [9]. All other reagents and chemicals were purchased from Sigma Chemical Co. (St. Louis, MO).

\section{Preparation and extraction of coffee beans samples}

Eight Arabica beans grown in Brazil, Colombia, Costa Rica, Ethiopia, Hawaii, Papua New Guinea and Puerto Rico and four Robusta beans grown in India and Vietnam were obtained from the Sustainable Perennial Crops Laboratory coffee collection (USDA, ARS). The species identity of all twelve coffee beans were verified using SNP markers as described previously [13]. Additionally, four Arabica and four Robusta beans were separately purchased from
Austin Chromatogr - Volume 6 Issue 1 - 2019 ISSN 2379-7975 | www.austinpublishing group.com Park et al. () All rights are reserved
Citation: Park JB, Wang YTT, Zhang D, Vega EF and Meinhardt WL. HPLC Quantification and MS/NMR Confirmation of Javamide-l/-II in Arabica and Robusta Coffee Beans from Different Regions for Finding Better Bean Sources for Javamide-I/-II. Austin Chromatogr. 2019; 6(1): 1051. 


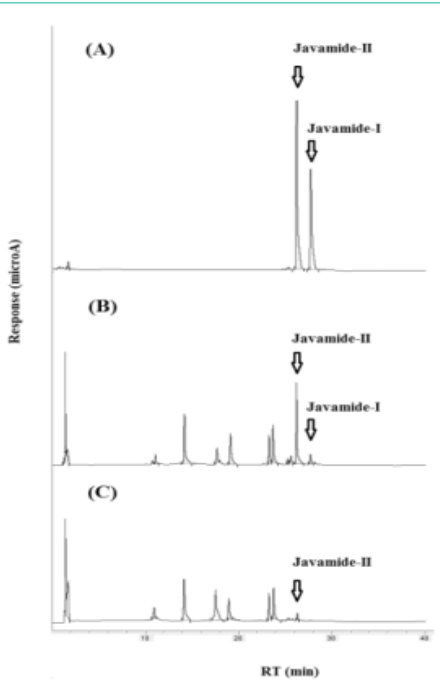

Figure 1: HPLC chromatograms of javamide-l/-II standards and the extract prepared from Arabica and Robusta samples. (A) Javamide-I/-II standards (6 $\mathrm{n}$ mole for javamide-I/-II). (B) The mixture of four Robusta (S9-12) extracted samples. (C) The mixture of ten Arabica (S1-8) extracted samples. The chromatograms were monitored using an electrochemical detector.

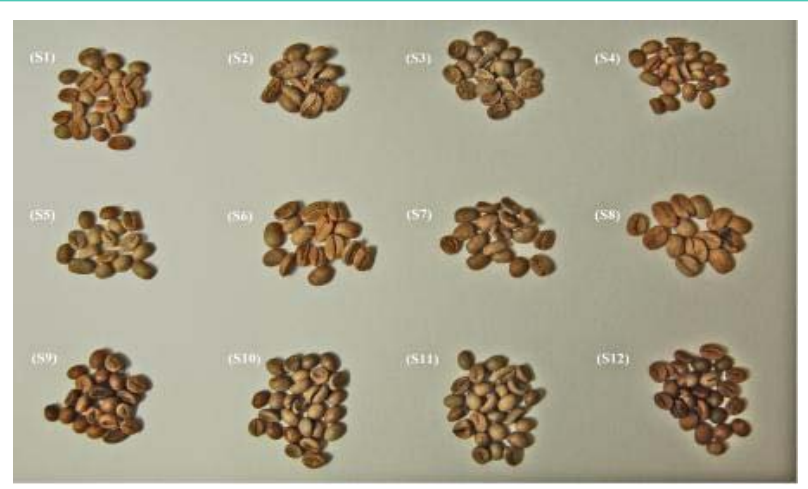

Figure 2: The pictures of twelve coffee beans used in the study. Coffee beans with regions and sample names; S1 (C. arabica; Brazil, Bourbon), S2 (C. arabica; Colombia, Gigante Maragogype), S3 (C. arabica; Costa Rica, Tarrazu), S4 (C. arabica; Ethiopian, Harrar), S5 (C. arabica; Ethiopian, Kaffa Forest Tega \& Tula), S6 (C. arabica; Guatemala, Typica), S7 (C. arabica; Papua New Guinea, Gumancha), S8 (C. arabica; Puerto Rico, Pergamino), S9 (C. canephora; India, Robusta bulk ), S10 (C. canephora; India, Robusta), S11 (C. canephora; India, Sufia Robusta ), S12 (C. canephora; Vietnam, Mocha Robusta).

online stores to validate the data for javamide-I/-II. All unroasted coffee beans were grinded with a coffee grinder, and then pulverized using a mortar and pestle. The resulting fine powder was extracted with $80 \%$ methanol ( $50 \mathrm{ml}$ per $1 \mathrm{~g}$ coffee bean) with a gentle shaking at room temperatures for $24 \mathrm{hr}$. Then, the samples were extracted three times, providing $1^{\text {st }}, 2^{\text {nd }}$ and $3^{\text {rd }}$ extraction samples. The extraction samples were utilized to isolate javamide-I/-II for HPLC, MS/MS and NMR analysis and determining the extraction recovery.

\section{High-Performance Liquid Chromatography (HPLC) analysis}

HPLC analysis was performed with a C18 column and a mixed step and linear gradient condition. Briefly, a $150 \mathrm{~mm} \times 4.6 \mathrm{~mm}$ i.d., $5 \mu \mathrm{m}$, Eclipse Plus C18 (Agilent, Santa Clara, CA) was used as the stationary

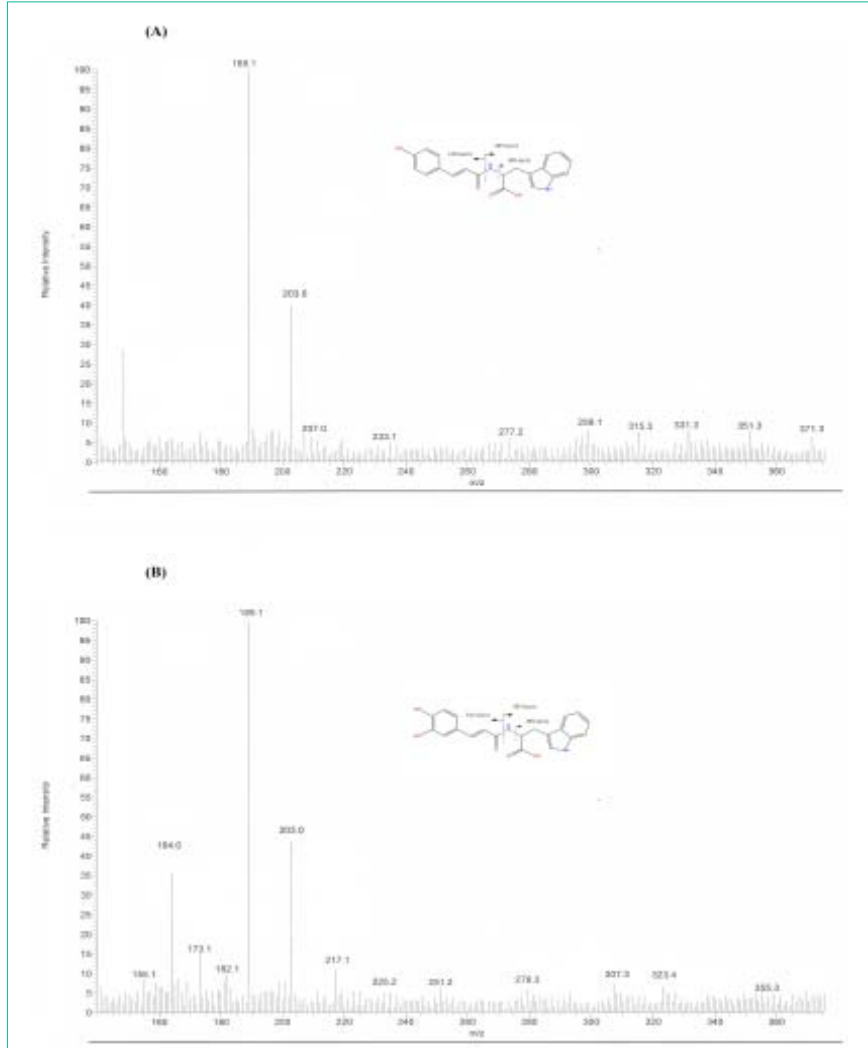

Figure 3: LC MS/MS Mass Spectra. The mass spectra were measured with Electrospray Ionization (ESI) on a Water MicroMass TQD Tandom Mass Spectrometer running under Waters Empower 3 Chromatography Data Software. The javamide-I (A)/-II (B) were analyzed using the following mass transitions given in parentheses: $(\mathrm{m} / \mathrm{z})$.

phase to analyze the standards and coffee samples. The samples were separated using a mobile-phase condition; buffer A ( $5 \mathrm{mM}$ phosphate, $\mathrm{pH}$ 5) for 0-2 min, $5 \%$ buffer B (60\% acetonitrile) for 2-5 min, a linear gradient from $5 \%-100 \%$ buffer B (60\% acetonitrile) for 5-35 min, and buffer $\mathrm{B}$ for $5 \mathrm{~min}(1 \mathrm{~mL} / \mathrm{min})$. The samples were injected by an autosampler into an Alliance 2690 HPLC system (Waters, Milford, MA), and were monitored by a CoulArray electrochemical detector with four electrode channels (ESA, Chelmsford, MA).

\section{Liquid Chromatography-Mass Spectrometry (LC-MS/MS)}

The LC MS/MS mass spectra were measured with Electrospray Ionization (ESI) on a Water MicroMass TQD Tandom Mass Spectrometer running under Waters Empower 3 Chromatography Data Software.

\section{Nuclear Magnetic Resonance (NMR) analysis}

The peaks of javamide-I/-II were isolated from the coffee samples using the method described previously $[8,9]$. The chemical structures of javamide-I/-II were verified using NMR spectroscopic methods. NMR samples were prepared by dissolving javamide-I/-II $(20 \mathrm{mg})$ in d6-DMSO $(0.75 \mathrm{~mL}) .1 \mathrm{H}$ and $13 \mathrm{C}$ spectra were acquired at ambient temperature on the JEOL BCX-400 NMR spectrometer operating 400 $\mathrm{MHz}$ for $1 \mathrm{H}$ and $100 \mathrm{MHz}$ for $13 \mathrm{C}$.

\section{Quantification of javamide-I/-II in coffee beans}

Twelve coffee beans obtained from the Sustainable Perennial 
Table 1: Regions and sample names for the Arabica and Robusta coffee beans used in the study. S1-8 samples from Arabica beans and S9-12 samples from Robusta beans.

\begin{tabular}{|c|c|c|c|}
\hline Sample & Species & Regions & Sample Names \\
\hline S1 & C. arabica & Brazil & Bourbon \\
\hline S2 & C. arabica & Colombia & Gigante Maragogype \\
\hline S3 & C. arabica & Costa Rica & Tarrazu \\
\hline S4 & C. arabica & Ethiopian & Harrar \\
\hline S5 & C. arabica & Ethiopian & Kaffa Forest Tega \& Tula \\
\hline S6 & C. arabica & Guatemala & Typica \\
\hline S7 & C. arabica & Papua New Guinea & Gumancha \\
\hline S8 & C. arabica & Puerto Rico & Pergamino \\
\hline S9 & C. canephora & India & Robusta bulk \\
\hline S10 & C. canephora & India & Robusta \\
\hline S11 & C. canephora & India & Sufia Robusta \\
\hline S12 & C. canephora & Vietnam & Mocha Robusta \\
\hline
\end{tabular}

Crops Laboratory coffee collection (USDA, ARS) were individually analyzed using the HPLC method as described in "Materials and Method". Since the extraction was performed three times $\left(1^{\text {st }}, 2^{\text {nd }}\right.$ and $\left.3^{\text {rd }}\right)$, the $1^{\text {st }}, 2^{\text {nd }}$ and $3^{\text {rd }}$ extraction samples were individually analyzed to determine the amounts of javamide-I/-II in each extraction. In addition, additional eight coffee beans were separately purchased from online stores and the extraction was prepared as described in "Materials and Methods". The amounts of javamide-I/-II were quantified using Coul Array electrochemical detector with four electrode channels (ESA, Chelmsford, MA).

\section{Statistical analysis}

All statistic analyses were performed with the SigmaPlot 11.0 (Chicago, IL). Data points in all figures were represented as the mean \pm SD of five measurements for each sample. $P$ value was calculated using one-way ANOVA with Holm-Sidak method and $P<0.05$ was considered as statistically significant.

\section{Results}

\section{Development and validation of HPLC method}

The HPLC, mobile-phase and detector conditions were developed for optimizing the detection, separation, resolution and reproducibility of the peaks of javamide-I/-II in the chromatography as described in "Materials and Methods". Using the developed HPLC method, javamide-I/-II standards were reliably separated and detected with fine separation and resolution; total HPLC running time for the assay was $40 \mathrm{~min}$, and javamide-I/-II were detected at a retention time of 27.7 and 26.5 min, respectively (Figure $1 \mathrm{~A}$ ). To validate the HPLC method, standard samples of javamide-I/-II (0-400 pmol) were prepared and HPLC assay was conducted. The detection limit was approximately $<5$ pmol with SD lower than $15 \%$. In this standard curve, satisfactory linear responses $(n=4)$ for the amides were obtained at the concentrations between 5 to 400 pmol (correlation coefficient $(\mathrm{R})=0.998)$. Also, intra-assay and inter-assay precision of the method was evaluated as described previously [8] (Data not shown here).
Table 2: The amounts and recovery of javamide-I/-II in twelve coffee samples. The amounts and recovery of javamide-I (A) and javamide-II (B). Coffee extract samples (S1-12) were individually extracted twice with $80 \% \mathrm{MeOH}$ extracts $(50 \mathrm{~mL})$ as described in "Materials and Methods", providing the $1^{\text {st }}, 2^{\text {nd }}$ and $3^{\text {rd }}$ extracts. The amounts of javamide-l were presented as $\mathrm{mg}$ per $1 \mathrm{~g}$ unroasted coffee sample $(n=5)$ and recovery ratio $(\%)=\left(1^{\text {st }}+2^{\text {nd }} / 1^{\text {st }}+2^{\text {nd }}+3^{\text {rd }}\right) \times 100$.

(A)

\begin{tabular}{|c|c|c|c|c|}
\hline Sample & $1^{\text {st }}(\mathrm{mg} / \mathrm{g})$ & $2^{\text {nd }}(\mathrm{mg} / \mathrm{g})$ & $3^{\text {rd }}(\mathrm{mg} / \mathrm{g})$ & Recovery ratio (\%) \\
\hline S1 & ND & ND & - & - \\
\hline S2 & ND & ND & - & 100 \\
\hline S3 & $0.04 \pm 0.01$ & ND & - & - \\
\hline S4 & ND & ND & - & 100 \\
\hline S5 & $0.05 \pm 0.01$ & ND & - & 100 \\
\hline S6 & $0.04 \pm 0.02$ & ND & - & 100 \\
\hline S7 & $0.04 \pm 0.01$ & ND & - & - \\
\hline S8 & ND & ND & - & 100 \\
\hline S9 & $0.72 \pm 0.08$ & $0.04 \pm 0.01$ & ND & 100 \\
\hline S10 & $0.77 \pm 0.09$ & $0.04 \pm 0.01$ & ND & 100 \\
\hline S11 & $0.76 \pm 0.08$ & $0.04 \pm 0.01$ & ND & 100 \\
\hline S12 & $0.38 \pm 0.06$ & $0.02 \pm 0.01$ & ND & - \\
\hline
\end{tabular}

(B)

\begin{tabular}{|c|c|c|c|c|}
\hline Sample & $1^{\text {st }}(\mathrm{mg} / \mathrm{g})$ & $2^{\text {nd }}(\mathrm{mg} / \mathrm{g})$ & $3^{\text {rd }}(\mathrm{mg} / \mathrm{g})$ & Recovery ratio $(\%)$ \\
\hline $\mathrm{S} 1$ & $0.16 \pm 0.02$ & $\mathrm{ND}$ & $\mathrm{ND}$ & 100 \\
\hline $\mathrm{S} 2$ & $0.14 \pm 0.02$ & $\mathrm{ND}$ & $\mathrm{ND}$ & 100 \\
\hline $\mathrm{S} 3$ & $0.15 \pm 0.02$ & $\mathrm{ND}$ & $\mathrm{ND}$ & 100 \\
\hline $\mathrm{S} 4$ & $0.14 \pm 0.01$ & $\mathrm{ND}$ & $\mathrm{ND}$ & 100 \\
\hline $\mathrm{S} 5$ & $0.27 \pm 0.03$ & $0.02 \pm 0.003$ & $\mathrm{ND}$ & 100 \\
\hline $\mathrm{S} 6$ & $0.17 \pm 0.02$ & $\mathrm{ND}$ & $\mathrm{ND}$ & 100 \\
\hline $\mathrm{S} 7$ & $0.16 \pm 0.02$ & $\mathrm{ND}$ & $\mathrm{ND}$ & 100 \\
\hline $\mathrm{S} 8$ & $0.08 \pm 0.01$ & $\mathrm{ND}$ & $\mathrm{ND}$ & 100 \\
\hline $\mathrm{S} 9$ & $4.56 \pm 0.51$ & $0.37 \pm 0.07$ & $\mathrm{ND}$ & 100 \\
\hline $\mathrm{S} 10$ & $4.26 \pm 0.56$ & $0.25 \pm 0.07$ & $\mathrm{ND}$ & 100 \\
\hline $\mathrm{S} 11$ & $4.25 \pm 0.50$ & $0.25 \pm 0.07$ & $\mathrm{ND}$ & 100 \\
\hline S12 & $3.31 \pm 0.48$ & $0.19 \pm 0.06$ & $\mathrm{ND}$ & 100 \\
\hline
\end{tabular}

\section{Extraction and recovery of javamide-I/-II in coffee bean samples}

The detail description of twelve coffee samples is shown in (Table 1) and their pictures are in (Figure 2). The samples were extracted as described in "Materials and Methods". After several preparations of coffee samples, $1 \mathrm{~g}$ coffee beans per $50 \mathrm{~mL} 80 \%$ methanol was found optimal for extraction and HPLC separation of javamide-I/-II in the samples. To determine the extraction recovery, the extraction was performed twice. The amounts of javamide-I in the 1st extraction were $95 \%$ higher than those of the $2^{\text {nd }}$ extraction, high enough for no subsequent 3 rd extraction (Table $2 \mathrm{~A}$ ). The recovery was determined by measuring the amounts following the addition of javamide-I standard $(0.2 \mathrm{mg})$ and found to be more than $98 \%$ (Table $2 \mathrm{~A}$ ). Similarly, the amounts of javamide-II in the $1^{\text {st }}$ extraction were $96 \%$ higher than those of the $2^{\text {nd }}$ extraction (Table $2 \mathrm{~B}$ ) and the recovery was found to be more than $98 \%$ (Table 2B). 


\section{MS/MS and NMR data of javamides-I/-II}

For MS/MS and NMR analysis, each peak of javamide-I/-II was purified from the Arabica (S1-10) and Robusta (S11-14) extracted samples using the HPLC method as described in "Materials and Methods". The MS/MS spectra of javamide-I/-II from Arabica and Robusta samples were measured in the ESI+ mode (Figure $3)$. The daughter ions ( $\mathrm{m} / \mathrm{z} 189$ and $\mathrm{m} / \mathrm{z} 203)$ corresponding to 3-(2-carboxyethyl)-1H-indol-1-ium and L-tryptophanate were observed as the base peaks in javamide-I and -II. However, the daughter ion (m/z 148.1; (E)-3-(4-hydroxyphenyl) acrylaldehyde) showed up in the spectrum of javamide-I (Robusta only) and the daughter ion (m/z 164.0; (E)-3-(3,4-dihydroxyphenyl)acrylaldehyde ion) appeared in the spectrum of javamide-II (Robusta and Arabica). All LC-MS/MS data supported that the compound was indeed javamide-I/-II. These MS/MS data were also confirmed by NMR data. The NMR data of javamide-I were the following: $1 \mathrm{H}$ NMR (d6DMSO, $400 \mathrm{MHz}) \delta 7.58((1 \mathrm{H}, \mathrm{d}, \mathrm{J}) 8.2 \mathrm{~Hz}, \mathrm{H}-18), 7.45$ ((1H, d, J ) 8.2 $\mathrm{Hz}, \mathrm{H}-1 / \mathrm{H}-5), 7.37$ ((1H, d, J ) $15.6 \mathrm{~Hz}, \mathrm{H}-7), 7.33((1 \mathrm{H}, \mathrm{d}, \mathrm{J}) 7.8 \mathrm{~Hz}$, H-15), 7.20 (1H, s, H-13), 7.06 ((1H, t, J ) $7.3 \mathrm{~Hz}, \mathrm{H}-16), 6.98$ ((1H, t, J ) $7.3 \mathrm{~Hz}, \mathrm{H}-17), 6.59((1 \mathrm{H}, \mathrm{d}, \mathrm{J}) 8.2 \mathrm{~Hz}, \mathrm{H}-2 / \mathrm{H}-4), 6.46((1 \mathrm{H}, \mathrm{d}, \mathrm{J})$ $15.6 \mathrm{~Hz}, \mathrm{H}-8), 4.72((1 \mathrm{H}, \mathrm{t}, \mathrm{J}) 7.3 \mathrm{~Hz}, \mathrm{H}-10), 3.24((1 \mathrm{H}, \mathrm{dt}, \mathrm{J})$ ) 6.0, 6.9 $\mathrm{Hz}, \mathrm{H}-11), 9.68$ (1H, br s, OH-a), 12.89 (1H, br s, OH-a'), $10.79(1 \mathrm{H}$, br s, NH-beta), 8.38 (1H, br s, NH-alpha); 13C NMR (d6-DMSO, 100 MHz) 174.7 (C, C-20), 166.8 (C, C-9), 157.5 (C, C-3), 141.7 (C, C-7), 136.4 (C, C-14), 130.6 (C, C-1), 130.6 (C, C-5), 127.9 (C, C-6), 127.4 (C, C-19), 124.0 (C, C-8), 123.0 (C, C-13), 121.7 (C, C-16), 119.8 (C, C-17), 118.8 (C, C-18), 115.7 (C, C-2), 115.7 (C, C-4), 111.5 (C, C-15), 109.3 (C, C-12), 60.3 (C, C-10), 28.2 (C, C-11). Based the NMR data, the structure of the isolated compound was determined as being coumaroyl-L-tryptophan (N-coumaroyltryptophan; javamide-I). Likewise, the NMR data for javamide-II were the following: $1 \mathrm{H} \mathrm{NMR}$ (d6-DMSO, $400 \mathrm{MHz}) \delta 7.58((1 \mathrm{H}, \mathrm{d}, \mathrm{J}) 8.2 \mathrm{~Hz}, \mathrm{H}-18), 7.33((1 \mathrm{H}, \mathrm{d}$, J ) $7.8 \mathrm{~Hz}, \mathrm{H}-15), 7.32((1 \mathrm{H}, \mathrm{d}, \mathrm{J}) 15.6 \mathrm{~Hz}, \mathrm{H}-7), 7.20(1 \mathrm{H}, \mathrm{s}, \mathrm{H}-13)$, $7.06((1 \mathrm{H}, \mathrm{t}, \mathrm{J}) 7.3 \mathrm{~Hz}, \mathrm{H}-16), 7.06(1 \mathrm{H}, \mathrm{s}, \mathrm{H}-5), 6.98((1 \mathrm{H}, \mathrm{t}, \mathrm{J}) 7.3$ $\mathrm{Hz}, \mathrm{H}-17), 6.82((1 \mathrm{H}, \mathrm{d}, \mathrm{J}) 8.7 \mathrm{~Hz}, \mathrm{H}-2), 6.67((1 \mathrm{H}, \mathrm{dd}, \mathrm{J})$ 8.2, 1.4 $\mathrm{Hz}, \mathrm{H}-1), 6.46((1 \mathrm{H}, \mathrm{d}, \mathrm{J}) 15.6 \mathrm{~Hz}, \mathrm{H}-8), 4.72((1 \mathrm{H}, \mathrm{t}, \mathrm{J}) 7.3 \mathrm{~Hz}$, $\mathrm{H}-10), 3.24$ ((1H, dt, J ) 6.0, $6.9 \mathrm{~Hz}, \mathrm{H}-11), 9.48(1 \mathrm{H}, \mathrm{br} \mathrm{s}, \mathrm{OH}-\mathrm{a}, \mathrm{b})$, 12.89 (1H, br s, OH-a'), 10.79 (1H, br s, NH-beta), $8.38(1 \mathrm{H}$, br s, NHalpha); 13C NMR (d6-DMSO, $100 \mathrm{MHz}) 174.7$ (C, C-20), 166.8 (C, C-9), 146.5 (C, C-3), 145.9 (C, C-4), 141.7 (C, C-7), 136.4 (C, C-14), 128.0 (C, C-6), 127.4 (C, C-19), 124.0 (C, C-8), 123.2 (C, C-1), 123.0 (C, C-13), 121.7 (C, C-16), 119.8 (C, C-17), 118.8 (C, C-18), 117.2 (C, C-2), 115.2 (C, C-5), 111.1 (C, C-15), 109.7 (C, C-12), 60.3 (C, C-10), 28.2 (C, C-11). Based on the NMR data, the structure of the isolated compound was determined as being (E)-(3-(3,4-dihydroxyphenyl) acryloyl)tryptophan (N-caffeoyltryptophan; javamide-II).

\section{HPLC quantification of javamide-I/-II in Arabica and Robusta beans}

For the quantification of javamide-I/-II, each coffee bean was individually extracted and prepared for HPLC analyses using the same extraction method described in "Materials and Methods". As shown in (Table 3), javamide-II was detected in all twelve samples $(0.08$ to $4.93 \mathrm{mg} / \mathrm{g})$, while javamide-I was detected in all four Robusta beans $(0.40-0.81 \mathrm{mg} / \mathrm{g}$ ), and only four Arabica beans (0.04 -0.05 $\mathrm{mg} / \mathrm{g}$ ). The data showed that the amounts of javamide-II in Robusta beans were more than 20 times higher than the average amount of
Table 3: The amounts of javamide-I/-II in the samples. The amounts were presented as $\mathrm{mg} / \mathrm{g}$ coffee sample $(n=5)$. $P$ value was calculated using one-way ANOVA with Bonferroni method and the marks $\left({ }^{*}\right)$ indicate statistical significance $(\mathrm{P}<0.05)$ verse Arabica samples $(\mathrm{S} 1-8)$. The marks $\left(^{* *}\right)$ indicate statistical significance $(P<0.05)$ between Robusta sample $(S 9)$ and Robusta sample $(S 12)$.

\begin{tabular}{|c|c|c|}
\hline Sample & Javamide-I $(\mathrm{mg} / \mathrm{g})$ & Javamide-II $(\mathrm{mg} / \mathrm{g})$ \\
\hline S1 & ND & $0.16 \pm 0.02$ \\
\hline S2 & ND & $0.14 \pm 0.02$ \\
\hline S3 & $0.04 \pm 0.01$ & $0.15 \pm 0.02$ \\
\hline S4 & ND & $0.14 \pm 0.02$ \\
\hline S5 & $0.05 \pm 0.01$ & $0.29 \pm 0.04$ \\
\hline S6 & $0.04 \pm 0.02$ & $0.17 \pm 0.02$ \\
\hline S7 & $0.04 \pm 0.01$ & $0.16 \pm 0.02$ \\
\hline S8 & ND & $0.08 \pm 0.01$ \\
\hline S9 & $0.76 \pm 0.08^{*}$ & $4.93 \pm 0.59^{*} / *$ \\
\hline S10 & $0.81 \pm 0.11^{*}$ & $4.51 \pm 0.63^{*}$ \\
\hline S11 & $0.80 \pm 0.09^{*}$ & $4.50 \pm 0.57^{*}$ \\
\hline S12 & $0.40 \pm 0.07^{*}$ & $3.50 \pm 0.55^{*}$ \\
\hline
\end{tabular}

Table 4: The amounts of javamide-I/-II were presented as $\mathrm{mg} / \mathrm{g}$ coffee sample $(n=4)$. The bold values indicate Robusta samples.

\begin{tabular}{|c|c|c|c|}
\hline Sample & Javamide-l/-II $(\mathrm{mg} / \mathrm{g})$ & Designation & Identities/Name \\
\hline A1 & $\mathbf{0 . 2 3} \pm \mathbf{0 . 0 3 / 3 . 3 5} \pm \mathbf{0 . 4 5}$ & Robusta & Philippine Robusta \\
\hline A2 & $0.04 \pm 0.01 / 0.11 \pm 0.03$ & Arabica & Colombia Arabica \\
\hline A3 & $0.08 \pm 0.02 / 0.31 \pm 0.06$ & Arabica & Indian Arabica \\
\hline A4 & $\mathbf{0 . 2 7} \pm \mathbf{0 . 0 4 / 2 . 3 1 \pm 0 . 3 2}$ & Robusta & Madagascar Robusta \\
\hline A5 & $\mathbf{0 . 4 5} \pm \mathbf{0 . 0 6 / 3 . 1 6} \pm \mathbf{0 . 4 9}$ & Robusta & Vietnam Robusta \\
\hline A6 & $0.04 \pm 0.01 / 0.19 \pm 0.04$ & Arabica & Mexico Arabica \\
\hline A7 & $0.03 \pm 0.01 / 0.12 \pm 0.03$ & Arabica & Nicaragua Arabica \\
\hline A8 & $1.12 \pm 0.12 / 4.50 \pm 0.62$ & Robusta & Indian Robusta \\
\hline
\end{tabular}

javamide-II in Arabica beans $(P<0.05)$.

\section{Influence of coffee bean cultivars on the amounts of javamide-I/-II}

The eight Arabica beans showed low levels and limited ranges of javamide-I ( 0.04 to $0.05 \mathrm{mg} / \mathrm{g}$ ) and javamide-II $(0.08$ to $0.29 \mathrm{mg} / \mathrm{g})$ compared to Robusta beans (Table 3). This result supports previous reports showing the lack of genetic diversity in Arabica cultivars [13] and the Arabica coffee germplasm in general (World Coffee Research, https://worldcoffeeresearch.org/work/measuring-genetic-diversitycoffea-arabica/). Related to geographical effects, the data showed that the production location appears not to have a major influence on the javamide levels especially in Arabica cultivars (Table 3). Compared to the Arabica beans whose uniformity differs greatly from the high heterogeneity of the Robusta samples, the four Robusta samples in this study had relatively high detectable levels of javamide-I ( 0.40 to $0.81 \mathrm{mg} / \mathrm{g}$ ) and javamide-II (3.50 to $4.93 \mathrm{mg} / \mathrm{g}$ ). Furthermore, the particular Robusta sample from India (S9) contains higher levels of javamide-II than the Robusta sample from Vietnam (S12), suggesting that there may be significant disparity in the amounts of javamide-II even in Robusta beans. 


\section{Investigation of Robusta coffee beans for better sources for javamide-I/-II}

Because the data showed that Robusta samples had relatively high levels of javamide-I/-II compared to Arabica samples, we explored Robusta species as candidate bean sources for javamide-I/-II. For this study, eight additional coffee beans (four Arabica and four Robusta beans) were purchased and the extraction and HPLC analysis was performed as described in "Materials and Methods". As expected, Robusta beans (A1, A4, A5 and A8) contained javamide-I/-II significantly higher than Arabica beans (A2, A3, A6 and A7) $(P<0.05)$ (Table 4). Once again, it was noticed that higher levels of javamideI/-II were found in Robusta beans from India than the Robusta beans from other regions (Vietnam, Philippine, Madagascar). These data were in line with the data from the twelve coffee beans that Robust beans contain more javamide-I/-II than Arabica beans, suggesting that Robusta beans may be better beans sources for javamide-I/-II than Arabica beans.

\section{Discussion}

Coffee is one of the most widely consumed beverages worldwide. Recent studies showed that coffee consumption is positively associated with potential beneficial effects on several human diseases [14-17]. Arabica and Robusta beans are two highly traded coffee beans cultivated in over 70 countries. There are a great number of Arabica cultivars, but the genetic diversity of this species is very limited due to the genetic bottle neck during its evolution and dispersal, as well as the nature of production by self-fertilization [18]. On the other hand, Robusta has a higher genetic diversity due to the wide geographical distribution, diverse wild populations and the nature of out-crossing [19]. Moreover, Robusta can be cultivated in lower altitudes and warmer climates than Arabica because Robusta is less susceptible to disease than Arabica [19,20]. Due to these differences in their genetic diversity and cultural practice, it is believed that the chemical composition of coffee beans may be influenced by genetic and cultivation factors. Javamide-I/-II are relatively new phenolic amides found in coffee beans [7-9]. Recently, they and derivatives were reported to contain several biological activities related to human health [9-12]. However, the influence of geographical impacts on amounts of javamide-I/-II is currently unknown in Arabica and Robusta beans. Therefore, in this paper, we investigated the quantities of javamide-I/-II in two most traded coffee species (Arabica and Robusta) and potential geographical influences on their amounts. Based on the data herein, javamide-I/-II may be found at higher levels in Robusta than Arabica beans, and the geographical regions (Ethiopia, Hawaii, Costa Rica, Colombia, Brazil, Argentina, Papua New Guinea, Vietnam) seem to have little effect on the javamide levels especially in Arabica varieties (Table 3). However, we noticed that the Robusta beans with India origin contains significantly higher levels of javamide-II than the Robusta beans from other regions (Tables 3,4), suggesting the possible heterogeneity of the Robusta coffee, although growing conditions and limited sample number cannot be discounted in the interpretation of the data. Therefore, in the future, further analysis of more coffee beans grown in different cultivated conditions may be required to reveal how growing conditions influence the levels of javamide-I/-II in coffee beans.

\section{Conclusion}

The data suggest that javamide-I/-II may be present at higher levels in Robusta beans than in Arabica, and Robusta species are likely to be better bean sources for javamide-I/-II than Arabica species.

\section{Acknowledgment}

This study was funded by USDA (project number 1235-51000054-00D).

\section{References}

1. Preedy WR (Ed.). Coffee in Health and Disease Prevention. Academic Press, New York. 2015

2. Garattini S (Ed.). Caffeine, Coffee, and Health. Raven Press, New York. 1993.

3. Wintgens JN (Ed.). Coffee: Growing, Processing, Sustainable Production. Wiley-VCH, Weinheim. 2004.

4. Vega FE. The rise of coffee, American Scientist. 2008; 96: 138-145.

5. Babova O, Occhipinti A, Maffei ME. Chemical partitioning and antioxidant capacity of unroasted coffee (Coffea arabica and Coffea canephora) of different geographical origin. Phytochemistry. 2016; 123: 33-39.

6. Speer K, Kölling-Speer I. Lipids. In Coffee: Recent Developments. Blackwel Science Ltd., Oxford. 2001.

7. Lean ME, Ashihara JH, Clifford MN, Crozier A. Purine alkaloids: a focus on caffeine and related compounds in beverages. Wiley-Blackwell, Chichester. 2012.

8. Park JB. NMR Confirmation and HPLC Quantification of Javamide-I and Javamide-II in Coffee Extract Products Available in the Market. Int J Anal Chem. 2017; 2017: 1927983.

9. Park JB. Finding potent Sirt inhibitor in coffee: isolation, confirmation and synthesis of javamide-II (N-Caffeoyltryptophan) as Sirt1/2 inhibitor. PLoS ONE. 2016; 11: e0150392.

10. Park JB. Javamide-I-O-methyl ester increases p53 acetylation and induces cell death via activating caspase $3 / 7$ in monocytic THP-1 cells, Phytomedicine. 2016; 23: 1647-1652.

11. Park JB, Wang TTY. Methyl (E)-(3-(3,4-dihydroxyphenyl)acryloyl) tryptophanate can suppress MCP-1 expression by inhibiting p38 MAP kinase and NF-kB in LPS-stimulated differentiated THP-1 cells. Eur J Pharmacol. 2017; 810: 149-155.

12. Park JB. In Silico Screening and In Vitro Activity Measurement of Javamide Analogues as Potential p38 MAPK Inhibitors. Int J Mol Sci. 2017; 18: E2704.

13. Zhou L, Vega FE, Tan H, Lluch AER, Meinhardt LW, Fang W, et al. Developing Single Nucleotide Polymorphism (SNP) markers for the identification of coffee germplasm, Tropical Plant Biology. 2016; 9: 82-95

14. Ludwig IA, Clifford MN, Lean ME, Ashihara H, Crozier A. Coffee: biochemistry and potential impact on health. Food Funct. 2014; 5: 1695-717.

15. O'Keefe JH, Bhatti SK, Patil HR, DiNicolantonio JJ, Lucan SC, Lavie CJ. Effects of habitual coffee consumption on cardiometabolic disease, cardiovascular health, and all-cause mortality. J Am Coll Cardiol. 2013; 62: 1043-1051.

16. Tajik N, Tajik M, Mack I, Enck P. The potential effects of chlorogenic acid, the main phenolic components in coffee, on health: a comprehensive review of the literature. Eur J Nutr. 2017; 56: 2215-2244.

17. Carman AJ, Dacks PA, Lane RF, Shineman DW, Fillit HM. Current evidence for the use of coffee and caffeine to prevent age-related cognitive decline and Alzheimer's disease. J Nutr Health Aging. 2014; 18: 383-392.

18. Anthony F, Combes MC, Astorga C, Bertrand B, Graziosi G, Lashermes P. The origin of cultivated Coffea arabica L. varieties revealed by AFLP and SSR markers. Theoretical and Applied Genetics Theor Appl Genet. 2002; 104: 894-900. 
19. Maurin O, Davis PA, Chester M, Mvung EF, Jaufeerally Fakim Y, Fay MF. Towards a phylogeny for Coffea (Rubiaceae): Identifying well-supported linkages based on nuclear and plastid DNA sequences. Ann Bot. 2007; 100: $1565-1583$.
20. Musoli P, Cubry P, Aluka P, Billot C, Dufour M, De Bellis F, et al. Genetic differentiation of wild and cultivated populations: diversity of Coffea canephora Pierre in Uganda. Genome. 2009; 52: 634-646.
Austin Chromatogr - Volume 6 Issue 1 - 2019

ISSN 2379-7975 | www.austinpublishing group.com

Park et al. (C) All rights are reserved
Citation: Park JB, Wang YTT, Zhang D, Vega EF and Meinhardt WL. HPLC Quantification and MS/NMR Confirmation of Javamide-I/-II in Arabica and Robusta Coffee Beans from Different Regions for Finding Better Bean Sources for Javamide-I/-II. Austin Chromatogr. 2019; 6(1): 1051. 